\title{
A educação escolar: um sistema de atividade articulando com outros sistemas
}

\author{
CÉLIA MAGALHÂES DE SOUZA*
}

\section{RESUMO}

Este artigo tem por objetivo mostrar como as diversas açóes desenvolvidas no sistema de atividade escolar podem impulsionar o objeto da atividade para um movimento de construçáo e reconstrução conjunta, permitindo, dessa forma, um novo olhar para a inclusão escolar dos alunos com necessidades educacionais especiais. Para tanto, procuro demonstrar como as açôes pedagógicas desenvolvidas em sala de aula, mediadas pela linguagem e outras ferramentas culturais construídas socialmente no ambiente escolar, podem promover a transformação nos sentidos e significados atribuídos à inclusão escolar, para que ela ocorra de fato e não somente de direito.

Palavras-chave: inclusão, escola, processo ensino-aprendizagem, educação especial, sala de aula.

\section{RESUMEN}

Este artículo tiene como objetivo mostrar como las diversas acciones desarrolladas en el sistema de actividad escolar pueden impulsar el objeto de la actividad para lograr un movimiento de construcción y reconstrucción conjunta, permitiendo, de esta manera, una nueva mirada hacia la inclusión escolar de los alumnos con necesidades educativas especiales. Con este fin, intento mostrar como las acciones pedagógicas desarrolladas en el aula, mediadas por el lenguaje y otras herramientas culturales construidas socialmente en el ambiente escolar, pueden promover

\footnotetext{
*Professora de Educação Física na E.E. Buenos Aires (celia_1961@yahoo.com.br).
} 
la transformación de los sentidos y significados atribuidos a la inclusión escolar, para que ella ocurra de hecho y no solamente por derecho.

Palabras clave: inclusión, escuela, proceso de enseñanza-aprendizaje, educación escolar, aula.

\section{ABSTRACT}

This article aims to show how the various actions developed in the school activity system can stimulate the object of the activity towards a movement of construction and reconstruction, allowing a new look towards the inclusion of pupils with educational special needs. For that purpose, I intend to demonstrate how the pedagogical actions developed in the classroom, mediated by language and by other cultural tools which are socially built in the school environment, can give rise to a change in the senses and meanings concerning school inclusion, so that actual inclusion occurs rather than just rightful inclusion.

Keywords: inclusion, school, teaching-learning process, special education, classroom. 


\section{INTRODUÇÃO}

Considerando os resultados apontados em minha pesquisa de mestrado (Souza, 2006), com base nas teorias de ensino-aprendizagem e nos estudos sobre defectologia de Vygotsky (1987), e os trabalhos desenvolvidos por Leontiev (1978) e Engeström (1999) sobre Teoria da Atividade, foi possível perceber que a escola inclusiva tem-se confrontado com um fluxo de forças externas e internas para a transformação das ações pedagógicas que promovam uma inclusão de fato e não somente de direito dos alunos com necessidades educacionais especiais, doravante NEE. Esse fluxo de forças externas e internas está representado pelos significados de inclusão social e escolar constituídos pela multivocalidade dos contextos sociais, nos quais estáo inseridos os participantes do processo ensino-aprendizagem. Por sua vez, esses significados estáo representados pelas barreiras sociais como, por exemplo, o preconceito e pelas açóes desenvolvidas pelo professor em sala de aula que permitam, por meio das práticas discursivas e formas colaborativas de comportamento - socialmente construídas no ambiente escolar e mediadas por artefatos culturais -, uma orquestração e reorquestração na interação dos sistemas de atividade.

Engeström (1999) argumenta que cada sistema de atividade tem o seu objeto 1 , que se transforma em um objeto 2 , construído pelo sistema de atividade e tem um significado coletivo. $\mathrm{O}$ objeto 3 é resultado da interação entre os dois sistemas de atividade, na qual as açóes são reformuladas e revistas, à medida que as pessoas agem, ou seja, existe um movimento de construção e reconstrução conjunta, entre os sistemas de atividade, permeado pelas contradiçóes que permitem ao objeto se reformular e se transformar em novo objeto.

Nessa perspectiva, considero a educação escolar um sistema de atividade, intermediado pelas diversas atividades desenvolvidas na escola, que interage com os diversos sistemas de atividade que a permeiam, sejam eles, o trabalho, a comunidade ou outros. Este artigo tem por objetivo, portanto, mostrar como as diversas açóes desenvolvidas no sistema de atividade escolar podem impulsionar o objeto da atividade para um movimento de construção e reconstrução conjunta, permitindo dessa forma um novo olhar para a inclusão escolar dos alunos com NEE. Para tanto, procuro demonstrar como as açóes pedagógicas desenvolvidas em sala de aula podem promover uma transformação nos sentidos e significados para que propiciem uma inclusão de fato e não somente de direito.

Este artigo é dividido em três partes: 1) princípios teóricos da Teoria da Atividade; 2) a educação escolar como um sistema de atividade; 3) consideraçóes finais. 


\section{PRINCÍPIOS TEÓRICOS DA TEORIA DA ATIVIDADE}

Para entender os impactos psicológicos da atividade organizada nas condiçóes e sistemas sociais produzidos em e por tal atividade, os teóricos analisam o desenvolvimento da consciência nos cenários de atividade social prática. Essas perspectivas sobre atividade e o desenvolvimento humano nos encaminham para a Teoria da Atividade em que a mediação é um conceito fundamental.

Engeström (1999), em suas pesquisas sobre a Teoria da Atividade, utiliza como base os estudos teóricos de Vygotsky (2002), que conferiu particular importância às análises da inserção sociocultural e da linguagem como uma ferramenta cultural. Nessa perspectiva, a primeira geraçáo da Teoria da Atividade, segundo Daniels (2003, p.114), enfoca a análise da ação mediada que se preocupa "com o modo como os humanos empregam as ferramentas culturais em processos sociais e individuais". Engeström (1999) também mostra a importância da mediação por meio de ferramentas e signos ressaltada por Vygotsky:

Mediation by tools and signs is not merely a psychological idea. It is an idea that breaks down the Cartesian walls that isolate the individual mind from the culture and the society. ${ }^{1}$ (Engeström, 1999, p. 29)

Vindo ao encontro dos estudos teóricos realizados por Vygotsky (2002), Leontiev (1978) argumenta que o conceito de atividade refere-se a uma necessidade específica de um agente ativo (sujeito) que move o objeto em direção à necessidade e termina quando é satisfeita. Portanto, o conceito de atividade está diretamente ligado ao conceito de motivo, e o objeto é parte integrante da atividade e aparece de duas formas:

[...] first, in its independent existence, commanding the activity of the subject, and second, as the mental image of the object, as the product of the subject's "detection" of its properties, which is effected by the activity of the subject and cannot be effected otherwise. ${ }^{2}$ (p.10)

O trabalho de Leontiev sobre atividade envolveu a elaboração das noçóes de objeto e meta e da importância fundamental do objeto para uma análise da motiva-

\footnotetext{
${ }^{1}$ A mediação por meio de ferramentas e signos não é meramente uma ideia psicológica. É uma ideia que derruba os muros cartesianos que isolam a mente do indivíduo de sua cultura e da sociedade.

2 [...] primeiro, como ser independente, comandando a atividade do sujeito, e, segundo, como a imagem mental do objeto, resultado da apropriação de suas especificidades pelo sujeito, causada por sua atividade e somente por ela.
} 
ção. Ele estabeleceu a idéia de que as diferentes atividades são distinguidas por seus objetos, e que é a transformação do objeto/meta que leva à integração dos elementos do sistema de atividade.

Em seus estudos de expansão da Teoria da Atividade, Engeström (1999, p.23) ressalta a importância do trabalho de Leontiev que aponta para a emergência do diálogo e a ênfase na linguagem, a unidade original das açóes do trabalho e as interaçóes sociais. Argumenta, porém, que Leontiev estendeu a esfera de análise e direcionou sua atenção para as transformações acontecidas entre os níveis, e que proclamar, meramente, ser a atividade um nível superior de análise não ajuda. Leontiev também não elaborou como o modelo triangular de ação pode ser desenvolvido ou expandido em ordem, para representar a estrutura de um sistema de atividade coletiva.

$\mathrm{O}$ autor refere-se à ideia de que os humanos podem controlar seu próprio comportamento não em bases biológicas, mas usando e criando artefatos. Para tanto, cita Vygotsky (1978, p.42):

Because this auxiliary stimulus possesses the specific function of reverse action, it transfers the psychological operation to higher and qualitatively new forms and permits the humans, by the aid of extrinsic stimuli, to control their behavior from the outside. (apud Engeström, 1999, p. 29, grifos no original)

Também, para Engeström, a atividade é formação coletiva, sistêmica, com uma estrutura mediacional complexa. "Um sistema de atividade produz açóes e é realizado por meio de açóes, porém náo se reduz a elas. Os sistemas de atividade se desdobram por longos períodos de tempo sócio-histórico, muitas vezes assumindo a forma de instituições e organizações" (Engeström, 1999, p. 35).

Em outras palavras, segundo Daniels (2003, p. 120), para Engeström "a unidade de análise da Teoria da Atividade é a atividade ou prática conjunta", bem como, o processo de transformaçáo social e a natureza conflituosa da prática social. Pretende, portanto, desenvolver ferramentas para compreender os diálogos, as múltiplas perspectivas e redes de sistemas de atividade interativa. Essas redes, permeadas pela dialogicidade e multivocalidade, em que "as contradições e lutas ocorrem na definição do motivo e do objeto da atividade

\footnotetext{
${ }^{3}$ Em razão de esse estímulo auxiliar ter a função específica de ação reversa, ele transforma a operação psicológica em formas novas e qualitativamente superiores, e permite que os seres humanos, com o auxílio de estímulos extrínsecos, controlem seu comportamento a partir do exterior.
} 
demanda uma análise de poder e controle nos sistemas de atividade em desenvolvimento" (Daniels, 2003, p. 121).

O modelo desenvolvido por Engeström (1999, p. 35) sobre a Teoria da Atividade, propóe dois sistemas de atividade interativos. Cada sistema de atividade tem o seu objeto 1, que se transforma em um objeto 2, construído pelo sistema de atividade e tem um significado coletivo. $\mathrm{O}$ objeto 3 é resultado da interação entre os dois sistemas de atividade, na qual as açóes são reformuladas e revistas, à medida que as pessoas agem. Em outras palavras, existe um movimento de construção e reconstruçáo conjunta, entre os sistemas de atividade, permeado pelas contradiçóes que permitem ao objeto se reformular e se transformar em um novo objeto.

Segundo Daniels (2003, p. 123), Engeström resume a Teoria da Atividade em cinco princípios básicos:

1) o primeiro é de que um sistema de atividade coletivo, mediado por artefato e orientado para o objeto, visto em suas relaçóes de rede com outros sistemas de atividade, é assumido como a unidade primária de análise;

2) o segundo é o da multivocalidade dos sistemas de atividade;

3) o terceiro é o da historicidade;

4) o quarto é o papel central das contradiçóes como fontes de mudança e desenvolvimento;

5) o quinto proclama a possibilidade de transformaçóes expansivas nos sistemas de atividade.

\section{A EDUCAÇÃO ESCOLAR COMO UM SISTEMA DE ATIVIDADE}

Com base nos princípios teóricos apresentados acima, podemos considerar a educação escolar como um sistema de atividade, cujo objeto idealizado, para o qual esse sistema é orientado, está nos princípios da educação básica, apresentados na LDB 9394/96 (Brasil, 1996), que são a educação de qualidade para todos baseada no respeito à diversidade. Esse sistema também é permeado pela multivicolidade e historicidade dos diversos sujeitos envolvidos no processo ensino-aprendizagem, bem como pelos diversos artefatos mediadores como, por exemplo, a linguagem oral e escrita.

Em outras palavras, o sistema de atividade escolar é formado por diversas atividades, entre elas a aula ministrada pelo professor, que, por meio das regras, divisão de trabalho, artefatos mediadores e formas colaborativas de comportamento, deveria promover uma construção e reconstrução dos sentidos e significados dos sujeitos envolvidos no processo para uma transformação no objeto idealizado. 
Vale lembrar, Vygotsky (2002, p. 11) quando argumenta que a "linguagem é, antes de tudo, um meio de comunicação social, de enunciação e compreensão" e que a relação entre o homem e o mundo passa pela mediação do discurso, pela formação de ideias e pensamentos. Em outras palavras, o autor identifica a linguagem e a interação social que ela medeia, como o mecanismo que permite o desenvolvimento de processos psicológicos no indivíduo por meio da aquisição da experiência social e cultural e que orienta o homem no mundo objetivo.

Portanto, é através da linguagem e das relaçóes sociais e formas colaborativas de comportamento, desenvolvidas nas comunidades de prática nas quais a criança está inserida, que acontecem as relaçóes entre aprendizado e desenvolvimento. Cada assunto tratado na escola tem a sua própria relação com o curso do desenvolvimento da criança, relaçáo essa que varia à medida que a criança vai se apropriando do conhecimento.

Para o autor, o desenvolvimento humano, tanto para a criança deficiente como para aquela que não apresenta deficiência, também náo ocorre por meio da quantidade de conhecimento e maturação, mas sim por uma série qualitativa de transformaçóes, um processo complexo de integraçáo e desintegraçáo e de ganhos e perdas. Portanto, desenvolvimento é o resultado de um aprendizado socialmente construído, propiciado pelas relações sociais e internalização da cultura.

$\mathrm{Na}$ opinião de Vygotsky a exclusão traz consequências cognitivas e por isso enfatiza a importância da educaçáo social de crianças com NEE e o potencial da criança para o desenvolvimento normal. Defende também uma escola que se abstenha de isolar os alunos com NEE e que os integre, tanto quanto possível, na sociedade. Para isso, Vygotsky (1987, p.93) propóe que existam mudanças nas práticas sociais desenvolvidas na escola, de forma a náo marginalizar os alunos com NEE e também, formas suplementares de comunicação, como, por exemplo, no caso de crianças cegas, o uso de outros meios, instrumentos e maneiras para alcançar as mesmas metas.

Para Evans (2003), Van Der Veer e Valsiner (1999) e Daniels (2003), essas mudanças também são necessárias quando os autores, em seus estudos, afirmam que: "as funçóes superiores desenvolvem-se na ação mútua social através do uso de meios culturais, devemos concentrar nossos esforços em ajustar esses meios às diferentes necessidades das crianças defeituosas" (Van Der Veer; Valsiner, 1999, p.87).

Entretanto, ao analisar uma aula gravada na $2^{\text {a }}$ série do Ensino Médio de uma escola pública da rede oficial de ensino, foi possível perceber que as açóes pedagógicas do professor em sala de aula nos remetem a uma visão médica da deficiência 
com foco na limitação do aluno, desconsiderando a diversidade, e que o estudante com NEE acessa o conhecimento de forma diferenciada.

$\mathrm{O}$ aluno $\mathrm{R}$, foco da pesquisa, apresenta um diagnóstico de paralisia cerebral (PC) resultado de um dano ao cérebro, que leva à inabilidade e/ou à falta de coordenação motora, o que dificulta certos movimentos do corpo. Também, apresenta deficiência mental leve que resulta em dificuldade de aprendizagem, pois não é capaz de realizar todas as tarefas solicitadas pelos professores, e muitas vezes náo consegue acompanhar o raciocínio. Apresenta deficiência na fala, que dificulta sua comunicação, e também déficit na coordenação motora que torna difícil sua participação, não só nas atividades propostas em classe como também nas atividades esportivas da escola.

$\mathrm{O}$ professor $\mathrm{S}$ ministra aulas de Física nessa escola e declara estar totalmente de acordo que um aluno com NEE frequente uma classe regular de ensino, porém transfere ao Estado e à escola a responsabilidade de adequar as condiçôes físicas do estabelecimento para receber esses alunos, bem como a formação dos profissionais da educação.

Com base nos estudos de Engeström (1999), sobre Teoria da Atividade, considero a aula gravada uma atividade, coletiva e sistêmica, na qual tanto os alunos quanto o professor parecem estar engajados nas açóes de sala de aula, pois os alunos prestam atenção, discutem sobre o exercício proposto, fazem perguntas ao professor, que dá explicaçôes, mesmo quando não é solicitado, além de passar pelos grupos para ver o andamento dos trabalhos. Apresenta uma sistematização, não só na organização temática como na organização do espaço físico. Com relação à primeira, o professor tem um planejamento temático com um tópico discursivo definido e limitado. Quanto à segunda, a aula acontece em uma sala com as carteiras dispostas em fileiras e a mesa do professor encontra-se à frente da sala. Pela análise das açóes em sala de aula, é possível dizer que o professor e os alunos aceitam tal condição, visto que esse é o entendimento do gênero aula, construído socialmente na comunidade escolar. Percebe-se também, ainda segundo a perspectiva de Engeström, contradições quanto à definição do motivo e do objeto daquela atividade, reveladas pelas açóes do professor e dos alunos.

Analisando as ações desenvolvidas sob a perspectiva linguística, pela categoria de análise de turnos ${ }^{4}$, é possível perceber que o professor ao se posicionar à frente

${ }^{4}$ Galembeck (2003, p.65) expóe que na conversação os interlocutores se alternam no papel de falante e ouvinte, portanto pode-se caracterizar a conversaçáo "como uma série de turnos, entendendo-se por turno qualquer intervenção dos interlocutores (participantes do diálogo), de qualquer extensão" (Galembeck, 2003, p.71). 
da sala de aula, determinar o tópico discursivo, orientar e direcionar as atividades a serem realizadas assume o papel de controlador da atividade. Observa-se que o diálogo é assimétrico, pois o professor é o que inicia e organiza a aula, quando fala aos alunos: "vamos sentar/bom dia novamente", determinando o tópico a ser tratado, bem como estipulando os artefatos mediadores que serão utilizados para o desenvolvimento das tarefas.

Essa assimetria parece apontar para a divisão de papéis e para as regras estabelecidas naquele contexto, em que o professor assume o papel de condutor da ação pedagógica, oferecendo, assim, pouco espaço para a negociação com os alunos, que parecem aceitar tal condição.

Embora o professor deixe livre a escolha para que os alunos formem grupos ou não, o que pressupóe uma não imposição, parece não negociar com eles a construção colaborativa do conhecimento. Isso pode ser verificado quando o professor propóe uma sequenciação na qual indica os procedimentos a serem seguidos pelos alunos durante a atividade, bem como quando utiliza o modo imperativo, que é marcado pela determinaçáo de uma ordem, clara e com limites bem definidos, para estabelecer as regras da atividade.

No que se refere à divisão de trabalho, apesar de o professor utilizar o pronome nós, indicando para uma tarefa durante a qual as regras e a divisão de trabalho serão construídas de forma colaborativa, nas falas subsequentes, o uso do pronome eu"eu vou entregar pra vocês uma folha com dois exercícios que já...; eu quero que vocês façam o esboço do desenho geométrico" - aponta para a divisão de trabalho, centrada no controlador da atividade e não construída coletivamente.

Por meio do levantamento quantitativo de turnos, encontrei nessa atividade um total de 149 turnos, dos quais o professor (P) toma 74 deles, usando 37 turnos para a chamada, 12 turnos para falar sobre o conteúdo, 20 turnos para falar com a pesquisadora e 05 turnos para outros assuntos. Os demais 75 turnos ficam divididos entre 48 turnos dos alunos, sendo 37 turnos para responder a chamada, 04 turnos de tentativa de assalto e 07 turnos com passagem requerida. Os 27 turnos restantes são da pesquisadora (PE) respondendo ao P. Também é possível perceber que as interações se organizam de quatro maneiras: quando o P dá as instruçóes das tarefas, quando faz a chamada, quando fala com a PE e quando há o trabalho em grupo. Embora P, no decorrer da atividade, ande pela sala de aula e converse com os alunos sobre as dificuldades, ao olhar para os 04 turnos nos quais os alunos tentam algum tipo de participação na aula, é possível perceber que ao responder apenas com um “já vou, espera um pouco", parece existir a preocupação de P transmitir o conheci- 
mento, explicando os exercícios para todos os alunos, e não em explorar as tentativas de participaçáo deles, permitindo que exponham suas dúvidas ou necessidades, o que náo torna possível a explicitaçáo de conflitos que propicia a negociação entre as prováveis formas de desenvolver a atividade, e, assim, favorecer a construção coletiva e colaborativa do conhecimento.

Durante uma aula de 50 minutos, também existem 05 momentos nos quais o $\mathrm{P}$ demonstra preocupação em saber como $\mathrm{R}$ está desenvolvendo as tarefas propostas. Apesar de R não emitir nenhum sinal linguístico, é possível perceber, pela gravação em vídeo, que, por meio de gestos, demonstra estar atento à fala do P. Esses momentos, entretanto, indicam que o $\mathrm{P}$ se preocupa com a transmissão de conhecimento, pois fala para e não com $\mathrm{R}$, e que o objetivo da atividade está voltado para o resultado e não para o processo de construção conjunta do conhecimento, pois o $\mathrm{P}$ parece não negociar com $\mathrm{R}$ a resolução dos exercícios.

Diante do exposto, percebe-se que na atividade aula, o motivo, o objeto, as regras, a divisão de trabalho e o resultado esperado da atividade são determinados pelo professor, o que demonstra a preocupação com o cumprimento do planejamento anual e a transmissão do conteúdo e não a construção conjunta do conhecimento.

Também me leva a retomar os conceitos de Vygotsky sobre defectologia e ensino-aprendizagem, nos quais destaca a importância da não segregação dos alunos com NEE, e que é pela linguagem e pela interação social, que ela medeia, que ocorre o desenvolvimento de processos psicológicos no indivíduo, por meio da aquisição da experiência social e cultural. A atividade analisada demonstra, apesar de o professor propiciar oportunidades para que o aluno $\mathrm{R}$ (foco desta pesquisa) e também os outros participem formando grupos, que essa ação pedagógica não promove a construçáo de novos sentidos e significados, com um agir na e pela atividade, como, por exemplo, um novo modo de interação em sala de aula, no qual o objetivo da atividade fosse pautado no processo e não no resultado.

Em outras palavras, as açóes pedagógicas, desenvolvidas pelo professor na atividade aula, parecem não oferecer momentos que propiciem a reorganizaçáo da atividade educacional que contribua para a convivência com a diversidade e o pleno exercício da cidadania, não só do aluno com NEE, mas de todos os envolvidos no processo.

O sistema de atividade escolar, entretanto, nas suas relaçóes dialéticas com outros sistemas de atividade, deveria proporcionar atividades voltadas para a reconstrução dos sentidos e significados, cujo motivo, objeto, regras, divisão de trabalho e o resultado fossem consequência de formas colaborativas de comportamento entre 
professores e alunos. Essas formas colaborativas de comportamento devem estar pautadas no respeito à diversidade, ou seja, na aceitação, por parte do grupo, de que cada sujeito participante do processo ensino-aprendizagem tem uma forma de acessar o conhecimento.

Para tanto, em um sistema de atividade, o motivo, o objeto, as regras, a divisão de trabalho e o resultado devem ser negociados entre os participantes do processo ensino-aprendizagem, e, dessa forma, promover transformaçóes, eliminando as barreiras sociais e permitindo que aconteça a inclusão de fato e não somente de direito.

Com base nessa perspectiva, a atividade aula, por intermédio de seus conflitos, deveria impulsionar o sistema de atividade escolar, para que este orquestre e reorquestre suas práticas sociais. Por sua vez, o sistema de atividade escolar, na interação com outros sistemas de atividade, também provocará orquestraçóes e reorquestraçôes que vão se apresentar como novos significados e formas de atividades.

Portanto, na perspectiva da Teoria da Atividade, um trabalho pedagógico pautado nas formas colaborativas de comportamento, que se articule pela integraçáo de diversos sistemas de atividade e que nos remete aos ciclos expansivos, projeta o objeto da atividade para a transformação. Essa projeção permite que aconteçam as relaçóes dialéticas entre os sistemas de atividades, que, por meio de conflitos permeados pela dialogicidade e multivocalidade dos sujeitos envolvidos, provocam as transformaçóes, tanto no objeto da atividade como no próprio sistema de atividade.

\section{CONSIDERAÇÕES FINAIS}

Este artigo náo tem a pretensáo de esgotar as questóes que envolvem a inclusão dos alunos com $\mathrm{NEE}$, pois são muitas, ainda, as barreiras físicas e sociais a serem enfrentadas.

Porém, diante das teorias apresentadas é possível demonstrar a importância do uso da linguagem como um instrumento de mediação para promover a inclusão escolar, pois é por meio dela e das formas colaborativas de comportamento que ocorrem as transformaçóes em uma rede de sistemas de atividade que interagem entre si. Portanto, a escola sendo um dos sistemas de atividade que interage com outros sistemas, como, por exemplo, a comunidade escolar, ao promover mudanças nas açóes pedagógicas, pelo uso da linguagem como instrumento de mediação, propicia a inclusão de fato e não somente de direito. 
Inclusão, a meu ver, é propiciar condiçóes para que o aluno com NEE realmente se aproprie do conhecimento, para que possa enfrentar os desafios que o mundo lhe apresenta. Para se apropriar do conhecimento, o aluno precisa conhecer e vivenciar experiências diferenciadas em um ambiente heterogêneo, permeado de conflitos, que lhe permitam construir e reconstruir sua forma de ver o mundo e então se tornar um agente ativo na transformação das práticas sociais que deseja participar. (Souza, 2006, p.88)

Para que esta inclusão ocorra de fato, acredito que as mudanças na escola inclusiva devem primeiramente acontecer no âmbito dos participantes do processo ensino-aprendizagem, ou seja, são necessárias muitas transformaçôes na área da educação, e um dos caminhos que podem ser seguidos é o da mudança daqueles que estão diretamente envolvidos com a sala de aula.

O que se constata hoje é que, pautados pelo senso comum, os professores tendem a nivelar as diferenças reforçando as barreiras sociais, à medida que exercem pressão sobre os alunos com NEE para que se igualem aos "normais". Afora isso, esses sentidos e significados são construídos em razão do impacto que a deficiência causa na sociedade. A reação a esse impacto é também negativa para o desenvolvimento cognitivo dos alunos com NEE, pois pode levar a um complexo de inferioridade, à não-participação em atividades coletivas, à vontade de sair da escola, e muitas outras implicaçôes.

Portanto, os alunos com NEE devem ser vistos, pelos demais, como parceiros, embora, em alguns casos, necessitem de suporte diferenciado, como a máquina braile, ou ainda de mais tempo para escrever ou ler, porque têm condiçôes de aprender e de superar-se. É importante reconhecer essa necessidade de açóes diferenciadas, por parte da escola e da comunidade, pois os alunos com NEE, ao serem levados a se perceber como "iguais" aos outros, podem não só se sentir inferiores (pois dificilmente conseguiráo se igualar aos demais) como principalmente não se apropriar do conhecimento proposto pela escola, deixando assim de se superar e de atingir diferentes estágios de desenvolvimento o que lhes possibilitaria agir de forma inclusiva, nas diferentes práticas sociais a que têm acesso.

A escola, dita inclusiva, vê-se à frente do desafio de repensar suas práticas pedagógicas. Esse repensar precisa ser pautado nas formas de ação colaborativa, e assim determinar o nível de desenvolvimento potencial da criança, propiciando um movimento de construir e reconstruir as açóes pedagógicas, no qual professor e alunos podem planejar conjuntamente as tarefas a serem trabalhadas, pois as vozes 
que clamam por uma não-segregação, por uma educação de qualidade e por uma quebra das barreiras sociais não atingem somente alunos com NEE, visto que os problemas de aprendizagem não são vinculados apenas a fatores orgânicos, mas também a fatores sociais.

Para concluir, acredito que o professor, ao agir colaborativamente com os seus pares e alunos, tem contribuiçóes importantes que podem provocar essas mudanças no contexto escolar, por meio de ações pedagógicas que favoreçam a construção e reconstrução dos sentidos e significados atribuídos à inclusão escolar. Isso permitirá práticas sociais pautadas no respeito pela diversidade, não só as construídas no contexto escolar como também as construídas na articulação entre o sistema de atividade escolar e outros sistemas de atividade.

\section{REFERÊNCIAS BIBLIOGRÁFICAS}

BRASIL. Lei n. 9394, de 20 de dezembro de 1996. Estabelece as diretrizes e bases da educação nacional. Diário Oficial da União, Brasília, 23 dez. 1996.

DANIELS, Harry. Vygotsky e a pedagogia. Tradução Milton Camargo Mota. São Paulo: Loyola, 2003. 246 p.

ENGESTRÖM, Yrjö. Activity theory and individual and social transformation. In: ENGESTRÖM, Yrjö et al. Perspectives on activity theory. 3.ed. New York: Cambridge University Press, 1999. p. 19-38.

EVANS, Peter. Algumas implicações da obra de Vygotsky na educação especial. In: DANIELS, Harry. (Org.). Vygotsky em foco: pressupostos e desdobramentos. Tradução Elisabeth J. Cestari; Mônica Saddy Martins. 6.ed. Campinas: Papirus, 2003. p. 69-89.

GALEMBECK, Paulo de Tarso. O Turno conversacional. In: PRETI, Dino (Org.). Análise de textos orais. 6.ed. São Paulo: Humanitas, 2003. v. 1, p. 65-92. (Projetos paralelos)
LEONTIEV, A N. Activity, consciousness, and personality. 1978. Disponível em: <http://www. marxists.org.> Acesso em: 30 maio 2005. SOUZA, Célia Magalhães de. Dilemas da escola inclusiva. 2006. Tese (Mestrado em Linguística Aplicada). Pontifícia Universidade Católica de São Paulo, São Paulo.

VAN DER VEER, René; VALSINER, Jaan. Vygotsky: uma síntese. Tradução Cecília C. Bartalotti. São Paulo: Loyola, 1999. 479 p.

VYGOTSKY, Lev Semenovich. A Formação social da mente: o desenvolvimento dos processos psicológicos superiores. Tradução José Cipolla Neto; Luis Silveira Menna Barreto; Solange Castro Afeche. 6. ed. São Paulo: Martins Fontes, 2002. $191 \mathrm{p}$.

The Fundamentals of defectology: abnormal psychology and learning disabilities. Tradução Jane E. Knox; Carol B. Stevens. New York: Plenum Press, 1987. v. 2, 349 p. (The Collected Works of $L$. S. Vygotsky).

Recebido em: maio 2007

Aprovado para publicação em: janeiro 2009 
